\title{
Flavanone 3-hydroxylase (F3H) Expression and Flavonoid Localization in Nodules of Three Legume Plants Reveal Distinct Tissue Specificities
}

\author{
Benedicte Charrier, ${ }^{1}$ Hanh Trinh, ${ }^{1}$ Simone Poirier, ${ }^{1}$ Adam Kondorosi, ${ }^{1,2}$ and Pascal Ratet ${ }^{1}$ \\ ${ }^{1}$ Institut des Sciences Végétales, Centre National de la Recherche Scientifique, UPR40, Avenue \\ de la terrasse, 91198 Gif-sur-Yvette cedex, France; ${ }^{2}$ Institute of Genetics, Biological and Research \\ Center, Hungarian Academy of Sciences, 61701 Szeged, Hungary \\ Accepted 8 June 1998.
}

\begin{abstract}
A fusion of the promoter of the Medicago sativa flavanone3-hydroxylase gene to the gus reporter gene was introduced into three leguminous plants, M. truncatula, M. sativa subsp. varia, and Vicia hirsuta. Expression of this fusion was detected in the parenchyma cells surrounding the vascular tissues in the nodules of the Medicago spp. plants, correlating with the presence of flavonoid compounds detected in situ in these cells. In $V$. hirsuta nodules, the fusion was expressed in the meristematic region, where high accumulation of flavonoids could also be detected. Our results indicate that flavonoids of the dihydroflavonol pathway are not found in the same tissues of the nodules in these three species, where they may play different roles. In light of these results, the possible roles of the F3H products in this organ are discussed.
\end{abstract}

Additional keywords: cell wall, CHS, IFR, phytoalexins, rhizobia.

Leguminous plants are capable of establishing a nitrogenfixing, symbiotic interaction with rhizobia. This symbiosis takes place in a specialized organ, the root nodule, where molecular nitrogen is fixed by the bacteria into organic nitrogenous compounds (Mylona et al. 1995). Flavonoids are secondary metabolites produced by plants, and are mainly present in flowers as precursors of anthocyanins (McClure 1975; Holton and Cornish 1995). In leguminous plants, they are also produced in the root system and play various roles in plant-microbe interactions (Dixon and Paiva 1995; Shirley 1996). The excreted flavonoids are able to interact with the NodD protein of the microsymbiont, resulting in the activation of the nod and nol genes responsible for the synthesis and excretion of Nod factors (Schultze et al. 1994; Dénarié et al. 1996; Long 1996), which are able to trigger the early events of nodule development (Long 1996). In legumes, flavonoids are also phytoalexins and are produced in response to wounding or infection by pathogens (Dixon and Paiva 1995).

Corresponding author: Pascal Ratet; Telephone: 33-(0)1-69823605; Fax: 33-(0)1-69823695; E-mail: Pascal.Ratet@isv.cnrs-gif.fr

Present address of Benedicte Charrier: Department of Biology, University of Leeds, Leeds, LS2 9JT, U.K.
The flavonoid biosynthetic pathway (Fig. 1) has been extensively studied in numerous plants. In leguminous plants, the genes coding for the enzymes CHS, CHR, CHI, ChOMT, and IFR (chs, chr, chi, chomt, and ifr) are expressed at high levels in roots (Djordjevic et al. 1997; McKhann and Hirsch 1994; Maxwell et al. 1993; Paiva et al. 1991; Sallaud et al. 1995), whereas their expression in alfalfa nodules is lower than in the roots and limited to the Sinorhizobium meliloti-infected zone (Grosskopf et al. 1993; McKhann and Hirsch 1994), or to the meristematic region in the alfalfa (ifr; Oommen et al. 1994) and pea (chs; Yang et al. 1992) nodules. In alfalfa, these genes (chs, chi, and chomt) are involved in the synthesis of flavonoids acting as nod gene inducers (flavones, chalcones), as well as in the synthesis of phytoalexin precursors (isoflavones and derivatives; see Figure 1). The flavanones are key precursors of three types of flavonoid compounds: the isoflavones, the flavones, and the precursors of tannins and anthocyanins (Fig. 1). F3H is the first enzyme necessary for the synthesis

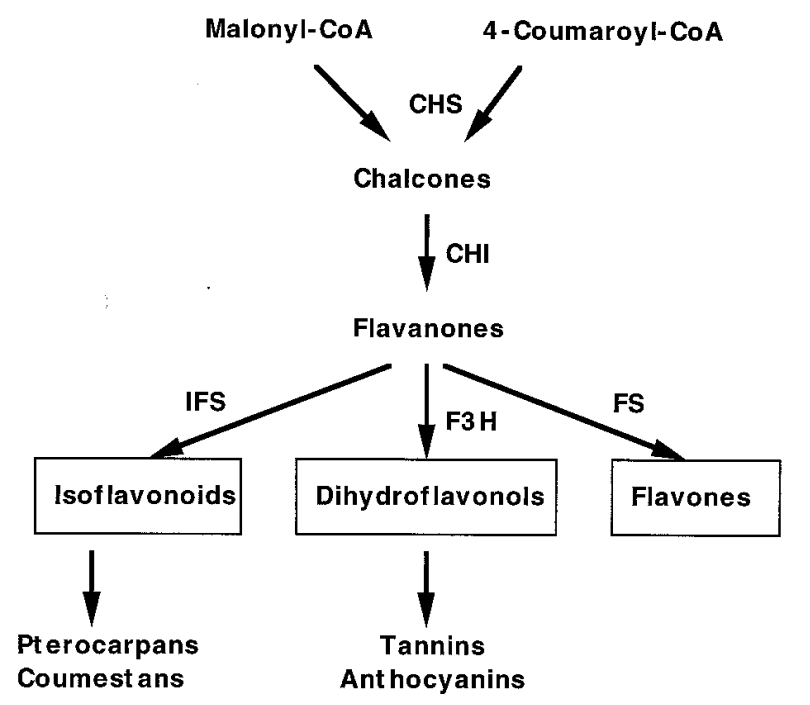

Fig. 1. Flavonoid biosynthesis pathway. Boxed compounds are derived from flavanones. CHS: chalcone synthase, $\mathrm{CHI}$ : chalcone isomerase, IFS: isoflavone synthase. F3H: flavanone-3-hydroxylase, FS: flavone synthase. 
of this last group of compounds. We have previously shown (Charrier et al. 1995) that the gene coding for this enzyme is expressed in Medicago sativa subsp. sativa at a higher level in nodules than in roots, in contrast to the chs and chi genes. This result was surprising since $f 3 h$ was thought to be expressed only in flowers. Moreover, $M$. sativa F3H does not participate in the synthesis of either the nod gene inducers or phytoalexins (Phillips et al. 1993; Tiller et al. 1994; Coronado et al. 1995; Dixon and Paiva 1995).

Using in situ hybridization (Charrier et al. 1995), we were unable, probably due to the low level of expression, to localize the site of expression of the $M s f 3 h$ gene in nodules, which could have helped us in the elucidation of its role in this organ. Therefore, in order to determine the spatial and temporal expression patterns of the $M s f 3 h$ gene in nodules, a fusion of its promoter with the gus reporter gene was constructed. By studying its pattern of expression first in a member of the Solanaceae, Nicotiana benthamiana, we showed that this construct was able to direct the expression of the gus reporter gene in cell types where flavonoids were detected in situ (Charrier et al. 1996). Thus, the expression pattern of the fusion reflected the expression pattern of the endogenous $f 3 h$ gene. Therefore, our aims were (i) to determine the cell-specific expression pattern of the Medicago sativa $f 3 h$ gene, by using this fusion, and (ii) to test the specificity of expression of this fusion in another leguminous plant, Vicia hirsuta. In contrast to $M$. sativa, V. hirsuta roots were shown to accumulate high amounts of glycoside derivatives of the dihydroxyflavonol kaempferol (Recourt et al. 1992), a product of F3H (Fig. 1), making this plant an interesting tool to study the expression pattern of the $f 3 h$-gus fusion in relation to the high flavonoid content of the nodule.

In this paper, the expression pattern of the $M$. sativa $f 3 h$ gene in nodules is presented. We show that the $f 3 h$ gene is specifically expressed in the cells surrounding the vascular tissues of Medicago spp. nodules, and describe for the first time its nodule-specific expression pattern. Moreover, this study revealed differences between Medicago spp. and V. hirsuta nodules in the pattern of expression of the $f 3 h$ gene and the accumulation of flavonoid compounds; in the latter plant, flavonoid accumulation and $f 3 h$ expression were detected in the meristematic region. The expression of the $f 3 h$-gus fusion was always associated with the presence of flavonoid compounds detected in situ.

\section{RESULTS}

A construct containing the promoter of one of the $M s f 3 h$ genes (Msf3h2) fused to the Escherichia coli gus reporter gene (Charrier et al. 1996) was introduced into M. sativa subsp. varia, M. truncatula, and V. hirsuta, using Agrobacterium tumefaciens for the Medicago spp. plants and A. rhizogenes for $V$. hirsuta. Transgenic roots and nodules induced by the symbiotic partner were then tested for $\beta$-glucuronidase (GUS) activity. In parallel, other samples of these plants were incubated in a solution of $\mathrm{AlCl} 3$ in order to localize the flavonoids under fluorescent light, allowing us to compare the sites of expression of the fusion and the sites of flavonoid accumulation (Charrier et al. 1996).

\section{Msf3h2-gus expression and flavonoid accumulation in M. truncatula.}

With the model legume M. truncatula R108-1 (Trinh et al. 1998) as recipient for transgene, the various nodulin (Lb, MsEnod12A, MsEnod12B) promoter-gus fusions always exhibited an expression pattern consistent with that of the endogenous gene (Trinh et al. 1998). After introduction of the Msf3h2 promoter-gusA fusion into R108-1, we regenerated nine independent $M$. truncatula transgenic plants. GUS activity was detectable in the nodules of only three of these plants. This result is unexpected but might reflect both the positional effect and the fact that the construct might be expressed at low level, as previously shown by the reverse transcriptionpolymerase chain reaction (RT-PCR) technique for the $M s f 3 h$ gene in M. sativa (Charrier et al. 1995). In the other regenerants, no GUS activity could be detected in other parts of the plant. In the plants where expression of the fusion was detectable, it was localized to the vascular tissue of the nodules but not in the roots (Fig. 2A). Nodule longitudinal sections (Fig. $2 \mathrm{~B})$ showed that the fusion was not expressed in the young vascular tissue and the level of expression increased toward the nodule base. The specific expression of the fusion in the nodule vascular system is illustrated in Figure $2 \mathrm{C}$, showing a longitudinal section of a root vascular system, from which nodule vascular bundles developed. Only the nodule vascular tissues showed GUS activity and this activity was observed at the sites where the two vascular systems diverged. A magnified nodule transversal section through a vascular tissue (Fig. 2D) showed that the xylem tissue was not stained while the surrounding cells corresponding to the vascular parenchyma appeared to be GUS positive.

To demonstrate that the expression of the chimeric gene represented the expression pattern of the endogenous $M s f 3 h$ gene, we tried to correlate it with the presence of flavonoids synthesized in this organ. However, with $\mathrm{AlCl} 3$ (Hariri et al. 1991) for staining, it was not possible to detect the most abundant flavonoids (isoflavone derivatives) present in $M$. truncatula (Harrison and Dixon 1994), due to their chemical nature. As described by Mabry et al. (1970), the detected fluorescence of these compounds results from the chelation of the metal ions by hydroxyl groups placed in ortho position or in the direct vicinity (position 3 or 5) of the carbonyl group in the $\mathrm{C}$ ring of the flavonoid molecule. As the flavonoids detected so far in Medicago spp. roots are 5-deoxyflavonoids and possess only one hydroxyl group per ring (for example, 7,4'-dihydroxyflavone; Phillips et al. 1993), they cannot chelate these ions and therefore cannot be visualized by this technique. In contrast, all $\mathrm{F} 3 \mathrm{H}$ substrates and products described so far are 5-hydroxy-flavonoids and should thus be detectable with $\mathrm{AlCl} 3$. Incubation of nodule sections in ethanol only displayed a blue color all over the nodule tissue (Fig. $2 \mathrm{E})$. In contrast, incubation of nodule sections in $\mathrm{AlCl} 3 /$ ethanol (Fig. 2F) did not reveal any specific fluorescence, confirming the lack of considerable staining of flavonoids with the $\mathrm{AlCl} 3$ reagent in the $M$. truncatula nodules. The xylem tissue, containing lignin and the nodule endodermis, exhibited a bright light-blue color under UV light, even when incubated only in ethanol. This blue fluorescence therefore does not correlate with the presence of flavonoids. The rest of the nonspecific fluorescence was extinguished by the $\mathrm{AlCl} 3$. However, a careful analysis of the stained tissue clearly revealed a faint 

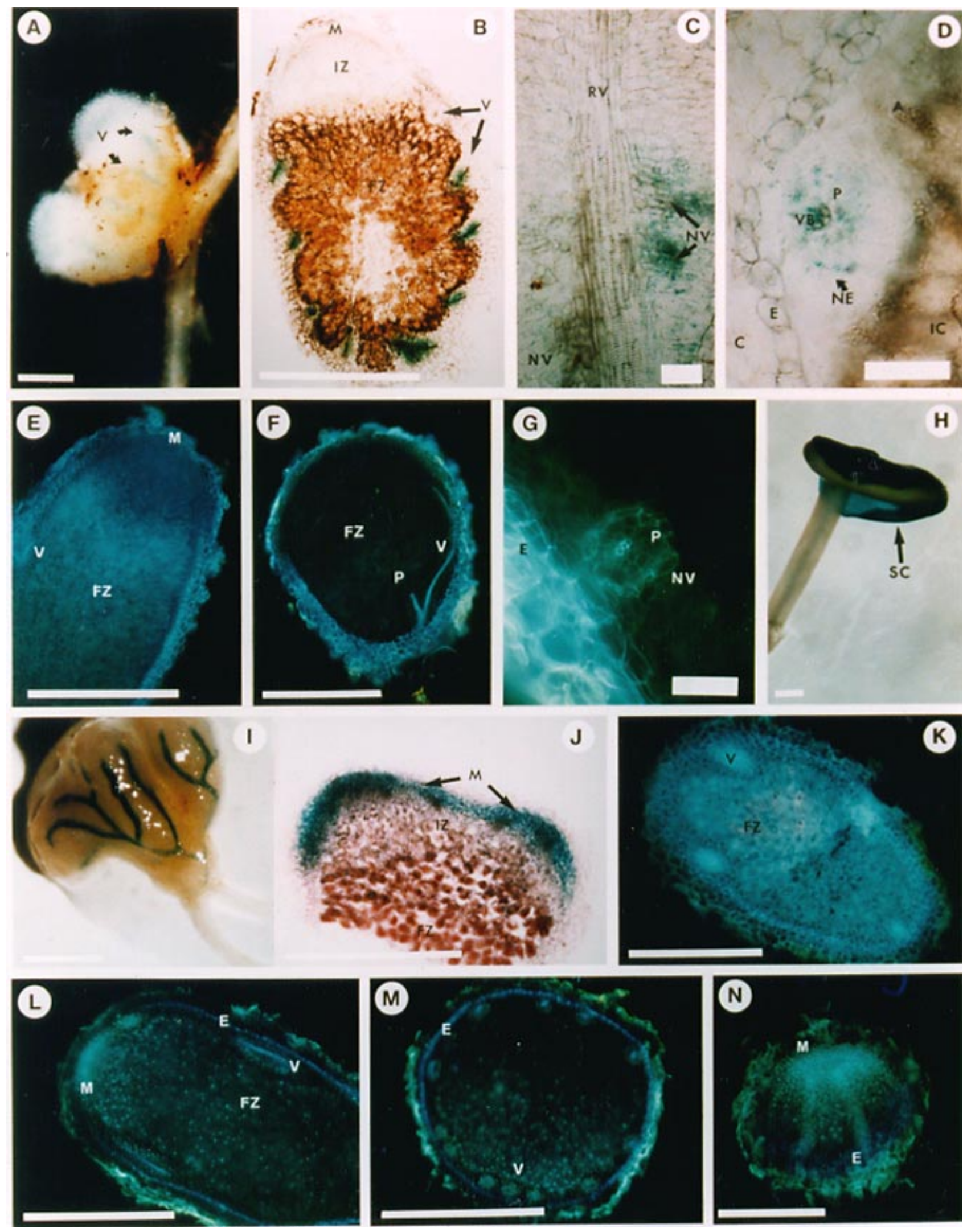
green-blue color specific for flavonoids and associated with cells surrounding the vascular tissue (Fig. 2F and G). Surprisingly, the green fluorescence seems to be associated with the cell wall (Fig. 2G), rather than being present in the vacuole where flavonoids generally accumulate (McClure 1975). This result indicates that flavonoids different from those described previously in Medicago spp. roots are present around the vascular tissue of nodules. The association of the flavonoids to the cell wall of these cells as well as their low level of accumulation, compared with $V$. hirsuta (see below), may explain why we were not able to detect these compounds in nodule extracts (Zuanazzi et al. 1998), and correlates with the low level of expression of the Msf3h2-gus fusion and of the $f 3 h$ gene as revealed by RT-PCR experiments (Charrier et al. 1995). This result also confirms that expression of the fusion is associated with the presence of flavonoids accumulating in the same cell type. We previously showed (Charrier et al. 1996) that the Msf3h2-gus fusion was expressed in the Nicotiana benthamiana seed coat, the site of tannin synthesis. In transgenic $M$. truncatula plants, GUS activity was also detected in the seed coat, correlating with the presence of tannins (products of the F3H activity; Fig. 1), as demonstrated by staining with the specific reagent DMACA (Li et al. 1996; Fig. $2 \mathrm{H}$ ). Moreover, in the progeny of the transformants GUS activity was also detected in tissues accumulating anthocyanins (data not shown), which are also derivatives of the $\mathrm{F} 3 \mathrm{H}$ activity (Fig. 1).

\section{Msf3h2-gus expression and flavonoid accumulation in M. sativa.}

To confirm the results obtained with the transgenic $M$. truncatula plants, the fusion was also introduced into the tetraploid plant $M$. sativa subsp. varia by A. tumefaciensmediated transformation. In this experiment, out of 18 regenerants, only six plants displayed a genomic restriction pattern consistent with the T-DNA restriction map, as determined by Southern blot analysis (data not shown). These six plants, which contained a single and intact copy of the T-DNA (data not shown), displayed GUS activity in flowers: gus expression was detected in petals, at the base of the sepals, in peduncle, in pollen grains, and in the base cells of the trichomes present on the peduncle and sepals (data not shown), which are organs known to accumulate flavonoids or anthocyanins. No GUS activity was detectable in the roots. However, one plant out of six, which showed the strongest GUS activity in flowers, displayed detectable GUS activity in the nodule vascular system as soon as it differentiated from the root vascular system (Fig. 2I). No expression could be detected in the meristematic region or other zones of the nodule. Though only one transgenic plant showing the nodule-specific pattern of expression of the fusion was obtained, it was in good agreement with the $M s f 3 h$ expression studies we performed previously on $M$. sativa subsp. sativa nodules with the RT-PCR technique (Charrier et al. 1995) and confirmed the pattern of expression found in the $M$. truncatula plants. To demonstrate that this pattern of expression was stable in the progeny of this regenerated plant, we crossed it with the compatible tetraploid plant $M$. sativa subsp. sativa cv. Sitel (Bauer et al. 1994) and assayed the progenies for the expression of the fusion. Out of 18 plants tested, six expressed the fusion and the pattern detected in nodules was the same as that described above (data not shown), indicating that this pattern was conserved in the progeny of the plants and probably did not result from an aberrant expression pattern in the primary regenerant. All the other plants of this progeny did not express the fusion in any part of the plant, indicating that they were not transgenic, as expected in the progeny of a cross between two tetraploid plants. Staining of the $M$. sativa nodules with $\mathrm{AlCl} 3$ gave results similar to those obtained with the M. truncatula plants (data not shown).

\section{Msf3h2-gus expression and flavonoid accumulation in $V$. hirsuta.}

To study the pattern of expression of the fusion in a plant synthesizing flavonoids requiring $\mathrm{F} 3 \mathrm{H}$ activity for their synthesis, $V$. hirsuta chimeric plants were constructed as described by Quandt et al. (1993). This system of chimeric plants was used successfully to study the regulation of genes expressed during symbiosis (Vijn et al. 1995). We obtained nontransgenic plants harboring a transgenic root system induced by A. rhizogenes that could be cotransformed with the T-DNA carrying the fusion and that could also be nodulated by R. leguminosarum bv. viciae (Quandt et al. 1993). In these plants, the Msf3h2-gus expression pattern was different from

Fig. 2. Msf3h2-gus expression and flavonoid localization in nodules of Medicago truncatula, M. sativa, and Vicia hirsuta plants. A-D, $\beta$-Glucuronidase (GUS) activity in $M$. truncatula transgenic plants expressing the $f 3 h$-gus fusion. A, Whole nodule with root segment showing specific expression of fusion in nodule vascular tissues. B, Nodule longitudinal section. Blue staining indicates expression of Msf3h2-gus fusion. C, X-gluc (5-bromo-4-chloro-3indolyl $\beta$-D-glucuronic acid) staining of a section going through junction between nodule (NV) and root (RV) vascular tissues at base of nodule. Only nodule vascular tissue expressed GUS activity as revealed by blue staining. D, Detail of transversal section through nodule vascular system; only parenchyma cells express fusion. Present are amyloplastes between nodule vascular tissue and infected cells of nitrogen fixation zone. E, M. truncatula nodule longitudinal section incubated in ethanol. Nonspecific blue fluorescence can be observed all over section. F-G, AlCl3/ethanol incubation of $M$. truncatula nodules. F, Nodule longitudinal section. Nonspecific blue fluorescence has disapeared; a faint green fluorescence is observed in parenchyma cells. G, Detail of section through nodule vascular system. Cell wall of nodule vascular tissue (NV) parenchyma cells (P) shows green fluorescence, indicating presence of flavonoids and contrasting with blue fluorescence of nodule endodermis (E). H, DMACA staining of a germinating $M$. truncatula seedling. Blue staining indicates presence of tannins in seed coat. I, $M$. sativa subsp. varia whole nodule staining showing specific nodule vascular expression of Msf3h2-gus fusion. No GUS activity can be detected in root tissues. J, X-gluc staining of nodule apical part of a transgenic V. hirsuta nodule expressing Msf3h2-gus fusion. K, Ethanol incubation of a wild-type $V$. hirsuta nodule longitudinal section. Nonspecific blue fluorescence can be observed all over section. L-N, AlCl3/ethanol staining of wild-type V. hirsuta nodules. L, Nodule longitudinal section. Green fluorescence is concentrated in meristematic region. M, Nodule transversal section. Flavonoids have accumulated in vascular tissue. This section probably goes through early nitrogen fixation zone. N, Nodule submeristematic section. Section probably goes from meristematic region (top) to early infection zone (bottom). A, amyloplasts; C, nodule cortex; E, endodermis; FZ, fixation zone; IC, bacteroid infected cell; IZ, infection zone; M, meristem; NE, nodule endodermis; NV, nodule vascular tissue; P, parenchyma; RV, root vascular system; SC, seed coat; V, vascular system; VB, vascular bundle. Thin bars = 1 mm. Thick bars $=150 \mu \mathrm{m}$. 
that observed in the Medicago spp. plants. In roots of nodulating plants, GUS activity was detected in the vascular bundle and in the elongation zone (data not shown), correlating with the presence of dihydroflavonol compounds in these roots (Recourt et al. 1992). In nodules, the Msf3h2-gus fusion was expressed at high level in the nodule meristematic region (Fig. 2J). GUS activity could not be detected in roots and nodules of chimeric plants transformed with the empty vector. In situ localization of flavonoids by incubation in $\mathrm{AlCl} 3$ / ethanol revealed the presence of a strong green fluorescence in the meristematic region (Fig. 2L and N) and in the vascular parenchyma (Fig. 2L and M), correlating thereby with the gus expression pattern. Incubation of the samples in ethanol was used as a control for the specificity of the $\mathrm{AlCl} 3$ staining (Fig. $2 \mathrm{~K}$ ), which revealed a blue fluorescence all over the nodule section. As shown in Figure 2L, the flavonoid staining was very intense in the meristematic region, revealing a significant accumulation of these compounds in this region. This strong staining seemed to progressively decrease toward the nitrogen fixation zone. This might suggest that these compounds are stable in the cells, but that their synthesis is restricted to the meristematic region, and thus they appear to be diluted by cell expansion after differentiation. Green fluorescence was also detected in the outer cortical cell layer of the V. hirsuta nodule, probably revealing the presence of flavonoids. In these sections, as previously observed with $M$. truncatula, the vascular bundles and the nodule endodermis showed a strong blue fluorescence nonspecific for flavonoids and probably resulting from the presence of lignin.

Interestingly, oblique sections through the meristematic region revealed a surprising distribution pattern of the flavonoids. They accumulated not only in the meristematic region, but also in discrete rows of cells that seemed to be aligned with the vascular tissue of the nodules (Fig. 2N). To our knowledge, such a pattern of cell arrangement in this region had not been previously described in indeterminate nodules.

\section{DISCUSSION}

\section{The Msf3h2-gus fusion is specifically expressed} in the vascular parenchyma of Medicago spp. nodules.

Earlier we showed (Charrier et al. 1996) that the pattern of expression of the Msf3h2 promoter-gus construct in Nicotiana benthamiana correlated with the distribution of flavonoid products in different cell types of the plant, indicating that this construct was valuable for further studies on the localization of flavonoids in different plant organs. In this paper, the analysis of nodules and roots of $M$. truncatula and $M$. sativa subsp. varia plants showed that this fusion is expressed in the cells surrounding the vascular tissues of nodules that form the vascular parenchyma. This expression is specific for the nodule because no expression could be observed in the root system and it correlates with the in situ localization of the flavonoids detected by the $\mathrm{AlCl} 3$ staining technique.

Despite numerous studies relating expression patterns of Medicago spp. genes in nodules (Bauer et al. 1996; Journet et al. 1994; Oommen et al. 1994, Pathirana et al. 1997), the Msf3h2-gus fusion revealed a new expression pattern. In other plants, numerous nodulin-encoding genes exhibiting various expression patterns have also been studied, but all these pat- terns are different from that observed with the Msf3h2-gus fusion (Pawlowski and Bisseling 1996; Munos et al. 1996). Transcripts for chi and ifr accumulate at a higher level in roots than in nodules (McKhann and Hirsch 1994; Paiva et al. 1991; Coronado et al. 1995). In addition, Grosskopf et al. (1993) have shown that chs is expressed at a higher level in nodules infected by a Rhizobium sp. mutant unable to fix nitrogen than in nodules infected by a wild-type Rhizobium sp. On the other hand, Vasse et al. (1993) have shown that defense reaction takes place in cells of the infection thread of an aborted nodule primordium. Altogether, these data led to the hypothesis that flavonoids accumulate in roots as well as in nodules and that this accumulation increased in nodules that were infected by mutant rhizobia unable to properly infect the nodule.

$\mathrm{F} 3 \mathrm{H}$ does not contribute to the synthesis of phytoalexins, and the parenchyma cells of the vascular system are not in contact with the microsymbiont or with any other soil bacteria present outside of the nodule (see Figure 2D). Therefore, its expression cannot be the result of an induced defense reaction, but it may be required for the synthesis of compounds permanently present in these cells. These compounds might halt the colonization of the complete organ or plant by the bacteria through the vascular system. Interestingly, the flavonoids detected in situ were localized in the cell wall. This cell wall localization is unusual for flavonoids but was reported in conifer (Strack et al. 1988) and grapevine leaves (Weber et al. 1995). This localization may indicate a role of these compounds in making these cells a mechanical barrier. As shown in Figure 2D, the parenchyma cells of the vascular system are sandwiched between the cells infected by Sinorhizobium melitoti (fixation zone) and the nodule endodermis, isolating them from the outer cortex, excluding also a role of $\mathrm{F} 3 \mathrm{H}$ in response to wounding or/and infections by soil bacteria or fungi. This cell wall localization seems to be specific for this organ since we have observed fluorescence in the vacuole of trichome cells of alfalfa with diphenylborinic acid ethanolamine ester and in the vacuole of the root hairs of another $M$. truncatula ecotype, with $\mathrm{AlCl} 3$ staining (data not shown). Thus, the fluorescence observed in the walls of nodule cells is probably not due to an artefact of microscopy or of the staining technique.

The expression of the Msf3h2-gus fusion in the parenchyma cells of the Medicago spp. nodule vascular system may also indicate a role for $\mathrm{F} 3 \mathrm{H}$ in nodule metabolism different from that in the roots. No function has been attributed so far to parenchyma cells surrounding the vascular tissues of nodules. However, their position between the vascular tissues and the nitrogen fixation zone in a region of high metabolic activity may suggest that these nodule parenchyma cells are involved in the transport of metabolites. Thus, flavonoids present in this tissue might interfere with the transport of metabolites through the phloem. Carbohydrates, serving as carbon sources for nitrogen fixation, are transported via the phloem from the leaves to the nodule. Once in the nodule, they are transported from the phloem cells to the fixation zone, crossing thereby the vascular parenchyma. In exchange, bacteroids reduce atmospheric nitrogen into ammonia, which is then converted into amino compounds in the plant cells and then transported from the cells of the nitrogen fixation zone to the phloem, again passing through the vascular parenchyma cells. Therefore, these cells are involved in the loading and unloading of nutri- 
ents for both partners, requiring various enzyme activities coupled to cellular processes that flavonoids might modulate. Vascular tissues transport other compounds besides nutrients, such as salts, hormones, or even water, whose supply may also be different in nodules and roots and might be affected by the presence of flavonoids. Indeed, various effects of $\mathrm{F} 3 \mathrm{H}$ substrates (flavanones) or products (flavonols and dihydroflavonols) on plant tissues were reported. They can affect root metabolism (Stenlid 1968) or enzyme activities (Stenlid 1963; Ravanel et al. 1990), or modulate hormonal action (Stenlid 1963; McClure 1975; Purohit et al. 1992; Jacobs and Rubery 1988). Hirsch et al. (1989) have shown that inhibitors of auxin transport trigger the development of pseudonodules as well as the expression of early nodulin genes, suggesting that flavonoids may act in nodule development as hormone transport inhibitors. However, there is no clear evidence so far that flavonoids are indeed able to disturb the transport of hormones in plants. Pharmacological studies also showed that flavonoids can have various effects on animal cells by modulating several enzyme activities or acting as powerful antioxidants (Akiyama et al. 1987; Zhang and Das 1994; Wang et al. 1994; Droylefaix et al. 1993; Hu et al. 1994; Emim et al. 1994; Ramwell et al. 1964). Although the effects of flavonoids in plants are likely to be different from their effects in animals, their roles in plants can still be diverse. Elucidating the role played by $\mathrm{F} 3 \mathrm{H}$ in nodules will require the analysis of $\mathrm{F} 3 \mathrm{H}$ Medicago spp. mutants.

The expression patterns of the $M s f 3 h$-gus fusion in Medicago spp. and $V$. hirsuta plants are distinct, demonstrating the diversity of flavonoid accumulation between two leguminous plant genera.

In nodules of $V$. hirsuta carrying the $f 3 h$ promoter gus fusion, gus expression was detected in the meristematic region, correlating with the presence of flavonoids detected after incubation in $\mathrm{AlCl} 3$ solution. GUS activity was also detected in roots. In agreement with these results, Recourt et al. (1992) have shown that roots and nodules of $V$. hirsuta plants contain kaempferol glycosides as their most abundant flavonoids, which are products of $\mathrm{F} 3 \mathrm{H}$ activity. Therefore, $V$. hirsuta plants carrying this fusion display a GUS activity and a pattern of flavonoid accumulation different from that observed in the Medicago spp. plants.

In $M$. sativa subsp. varia roots and nodules, the product of F3H activity has not so far been detected by high-pressure liquid chromatography (HPLC; Zuanazzi et al. 1998). The most abundant compounds found in the root system are ononine and malonyl ononin, derivatives of the isoflavonoid pathway (Coronado et al. 1995). We suppose that kaempferol glycosides and isoflavonoid derivatives might play similar roles in $V$. hirsuta and Medicago spp. roots and nodules (see below). This hypothesis is in agreement with the pattern of expression observed for the ifr-gus construct in the meristematic region of M. sativa nodules (Oommen et al. 1994) as well as with the in situ localization of the chs transcripts in the meristematic region of pea nodules. These enzymes also participate in the synthesis of the major flavonoids ( or isoflavonoids) present in the roots of these plants. In V. sativa it was shown (Recourt et al. 1992) that the dihydroxyflavonol kaempferol is an inhibitor of nod gene expression. Therefore, the accumulation of this type of compounds in the meristematic region might inhibit its colonization by the symbiotic bacteria. Similarly, in Medicago spp. plants phytoalexin synthesis in the meristematic region could play the same role. Our studies also indicate that the same flavonoids are most abundant in both nodules and roots.

The pattern of flavonoid accumulation observed in the meristematic region of $V$. hirsuta nodules, revealing a specific pattern of cell distribution, has not been described previously in indeterminate nodules. If the rows of cells that accumulate flavonoids in this region are markers for meristematic activity, the organization of this meristematic region is more complex than previously described (Vasse et al. 1990). Alternatively, based on the disposition of these cells they might be responsible for the organization of the vascular tissues of the nodule, which is in line with the higher content of these compounds detected around this vascular tissue (Fig. 2L and M). Thus, the distribution of flavonoids revealed by this technique contrasts drastically with the pattern observed in Medicago spp. Interestingly, the decreased flavonoid content of the vascular system in $V$. hirsuta plants from the meristematic region toward the oldest part of the nodule correlates with the apparently inverse distribution of the $\mathrm{F} 3 \mathrm{H}$ products and Msf3h2-gus expression in the Medicago spp. nodules. Thus, the distribution of these two types of compounds (most abundant and less abundant flavonoids) seems to be complementary in this tissue. A scheme of the flavonoid distribution in nodules and roots of both plants is shown in Figure 3. It is interesting that in all Medicago spp., V. hirsuta (this study), and Nicotiana benthamiana (Charrier et al. 1996) plants tested, the Msf3h2gus fusion was expressed in cells accumulating flavonoids, indicating that the regulatory elements of this promoter are recognized in these plants. Thus, in the different cell types of these plants, a common regulatory circuit might regulate the accumulation of these compounds.

Our study confirms that in symbiosis flavonoids might also play roles other than those suggested by Franssen et al. (1992), namely, the alteration of the hormonal balance leading to cortical cell divisions, and opens a new area for prospective studies on the role of flavonoids in leguminous plants.

\section{MATERIAL AND METHODS}

\section{Construction of the $M s f 3 h 2$ promoter-gus fusion.}

The construction of the Msf3h2-gus fusion was reported previously (Charrier et al. 1996).

\section{Transformation of leguminous plants.}

The diploid M. truncatula R108-1 (Blondon et al. 1994) was transformed following the protocol established by Trinh et al. (1998). Independent transgenic plants were obtained by regenerating only one plant per leaf explant used for the transformation.

Transformation of the tetraploid $M$. sativa subsp. varia A2 (Deak et al. 1986) was performed via somatic embryogenesis on leaves, as described in Bauer et al. (1996). Transgenic $M$. sativa plants were analyzed by Southern blot, with $15 \mu \mathrm{g}$ of DNA per sample, digested with HindIII and SstI, and hybridized with a gus or nptII probe as described in Charrier et al. (1996). Crossing between the white flower $M$. sativa subsp. varia and the dark blue flower $M$. sativa subsp. sativa cv. Sitel plants was done manually after emasculation of $M$. sativa 
subsp. varia, with $M$. sativa subsp. sativa $\mathrm{cv}$. Sitel as a pollen donor. Because $M$. sativa is allogamous, the frequency of autofertilization is supposed to be low. Indeed, dark blue flower plants were obtained in the progeny, confirming that the cross was successful.

\section{Medicago}

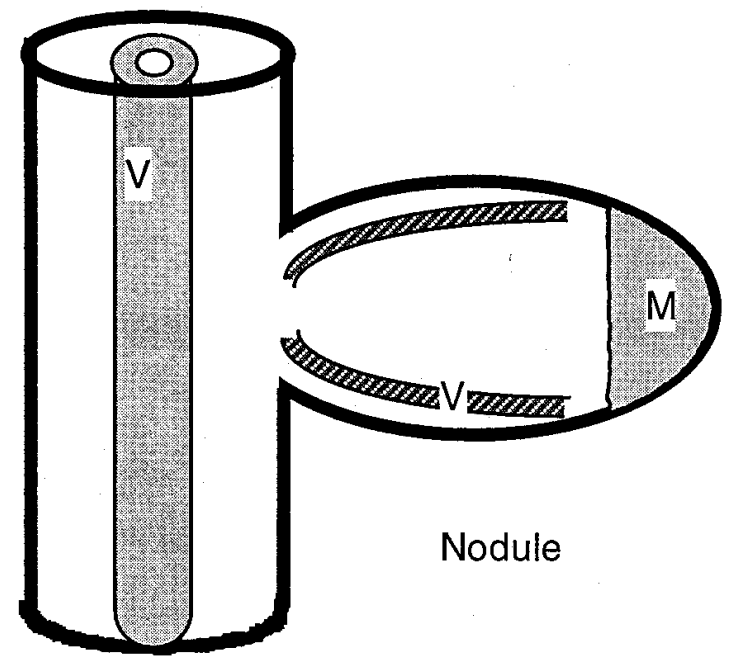

Root

\section{Vicia}

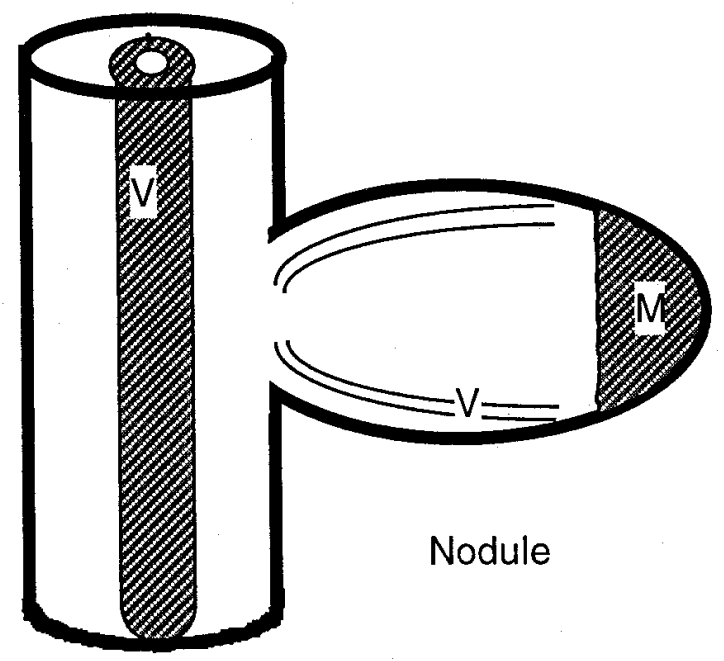

\section{Root}

Fig. 3. Schematic of localization of flavonoids and isoflavonoids in Medicago spp. and Vicia hirsuta nodules. The two plants accumulate different classes of phenolic compounds, which are flavonoids (hatched areas) or isoflavonoids (gray areas) in root system and in meristematic tissues of nodule. Medicago spp. plants accumulate dihydroflavonol derivatives (hatched areas) in vascular tissue. M, meristem; V, vascular tissue.
$V$. hirsuta chimeric plants (approximately 30) were obtained following the protocol of Quandt et al. (1993) and nodulation assays were performed as described in the Results.

\section{Nodulation assays.}

Transgenic plants were transferred from the tissue culture conditions to sand for a few weeks. Nodulation was performed in aeroponic boxes (Coronado et al. 1995) where plants were starved for nitrogen $(0.25 \mathrm{mM}$ nitrate) before inoculation with the appropriate Rhizobium strain. M. sativa subsp. varia and M. truncatula plants were inoculated with a culture of Sinorhizobium meliloti Rm41, as described in Charrier et al. (1995). $V$. hirsuta chimeric plants were grown in sand and inoculated with a culture of $R$. leguminosarum bv. viciae VH5e as described by Quandt et al. (1993).

\section{Histochemical localization of GUS activity.}

Nodules were harvested as described in Charrier et al. (1996). Sections of the samples $(100 \mu \mathrm{m})$ were generated with the Micro-Cut H1200 microtome (BioRad Laboratories, Hertfordshire, UK). GUS staining was performed on the sections or on intact tissues in $0.1 \mathrm{M}$ sodium phosphate buffer, $\mathrm{pH} 7.0$, supplemented with $1 \mathrm{mM}$ EDTA, $0.1 \%$ sodium dodecyl sulfate (SDS), and $0.2 \mathrm{mM} \mathrm{X-gluc} \mathrm{(5-bromo-4-chloro-3-indolyl-}$ $\beta$-D-glucuronic acid cyclohexylammonium salt; Biosynth, Staad, Switzerland). A Polyvar microscope (Reichert and Jung, Vienna) and an M420 binocular (Wild, Heerbrugg, Switzerland) were used for observation and photographic work.

\section{In situ localization of flavonoids.}

Wild-type fresh nodules embedded in $6 \%$ agarose were sectioned. Sections (90 to $100 \mu \mathrm{m}$ ) were cleared of the agarose layer and then incubated for $48 \mathrm{~h}$ in a solution of $\mathrm{AlCl} / \mathrm{etha}-$ nol and observed under epifluorescence microscope, as described in Charrier et al. (1996). Identical sections incubated in ethanol only were used as controls. The fluorescence was observed with a Polyvar epi-illumination microscope (Reichert and Jung) with a set of filters: 340 to $380 \mathrm{~nm}$ excitation / $430 \mathrm{~nm}$ suppression.

\section{ACKNOWLEDGMENTS}

We thank Claudine Deforeit for typing and Nathalie Mansion for photographic work.

\section{LITERATURE CITED}

Akiyama, T., Ishida, J., Nakagawa, S., Ogawara, H., Watanabe, S., Itoh, N., Shibuya, M., and Fukami, Y. 1987. Genistein, a specific inhibitor of tyrosine-specific protein kinase. J. Biol. Chem. 262:5592-5595.

Bauer, P., Crespi, M. D., Szécsi, J., Allison, L. A., Schultze, M., Ratet, P., Kondorosi, E. and Kondorosi, A. 1994. Alfalfa Enod12 genes are differentially regulated during nodule development by Nod factors and Rhizobium invasion. Plant Physiol. 105:585-592.

Bauer, P., Ratet, P., Crespi, M. D., Schultze, M., and Kondorosi, A. 1996. Nod factors and cytokinins induce similar cortical cell division, amyloplast deposition and MsEnod $12 \mathrm{~A}$ expression patterns in alfalfa roots. Plant J. 10:91-105.

Blondon, F., Marie, D., Brown, S., and Kondorosi, A. 1994. Genome size and base composition in Medicago sativa and M. truncatula species. Genome 37:264-270.

Charrier, B., Coronado, C., Kondorosi, A., and Ratet, P. 1995. Molecular characterization and expression of alfalfa (Medicago sativa L.) flava- 
none-3-hydroxylase and dihydroflavonol-4-reductase encoding genes. Plant Mol. Biol. 29:773-786.

Charrier, B., Leroux, C., Kondorosi, A., and Ratet, P. 1996. The expression pattern of alfalfa flavanone-3-hydroxylase promoter-gus fusion in Nicotiana benthamiana correlates with the presence of flavonoids detected in situ. Plant Mol. Biol. 30:1153-1168.

Coronado, C., Zuanazzi, J., Sallaud, C., Quirion, J. C., Esnault, R., Husson, H. P., Kondorosi, A., and Ratet, P. 1995. Alfalfa root flavonoid production is nitrogen regulated. Plant Physiol. 108:533-542.

Deak, M., Kiss, G. B., Koncz, C., and Dudits, D. 1986. Transformation of Medicago by Agrobacterium mediated gene transfer. Plant Cell Rep. 5:97-100

Dénarié, J., Debéllé, F., and Promé, J.-C. 1996. Rhizobium lipo-chitooligosaccharide nodulation factors. Annu. Rev. Biochem. 65:503-535.

Dixon, R. A., and Paiva, N. L. 1995. Stress-induced phenylpropanoid metabolism. Plant Cell 7:1085-1097.

Djordjevic, M. A., Mathesius, U., Arioli, T., Weinman, J. J., and Gärtner E. 1997. Chalcone synthase gene expression in transgenic subterranean clover correlates with localised accumulation of flavonoids. Aust. J. Plant Physiol. 24:119-132.

Droylefaix, M., Szabo, M., and Doly, M. 1993. Ischaemia and reperfusion-induced injury in rat retina obtained from normotensive and spontaneously hypertensive rats. Effects of free radical scavengers. Int. J. Tissue React. 15:85-91.

Emim, J., Oliveira, A., and Lapa, A. 1994. Pharmacological evaluation of the anti-inflammatory activity of a Citrus bioflavonoid, hesperidin, and the isoflavonoids, duartin and claussequinone, in rats and mice. $\mathrm{J}$. Pharm. Pharmacol. 46:118-122.

Franssen, H. J., Vijn, I., Yang, W. C., and Bisseling, T. 1992. Developmental aspects of the Rhizobium-legume symbiosis. Plant Mol. Biol. 19:89-107.

Grosskopf, E., Thi Cam Ha, D., Wingender, R., Rohrig, H., Szecsi, J., Kondorosi, E., Schell, J., and Kondorosi, A. 1993. Enhanced levels of chalcone synthase in alfalfa nodules induced by Fix ${ }^{-}$mutant of Rhizobium meliloti. Mol. Plant-Microbe Interact. 6:173-181.

Hariri, E. B., Salle, G., and Andary, G. 1991. Involvement of flavonoids in the resistance of two poplar cultivars to mistletoe (Viscum album L.). Protoplasma 162:20-26.

Harrison, M. J., and Dixon, R. A. 1994. Spatial patterns of expression of flavonoids/isoflavonoids pathway genes during interactions between roots of Medicago truncatula and the mycorrhizal fungus Glomus versiforme. Plant J. 6:9-20.

Hirsch, A. M., Bhuvaneswari, T. V., Torrey, J. G., and Bisseling, T. 1989. Early nodulin genes are induced in alfalfa root outgrowths elicited by auxin transport inhibitors. Proc. Natl. Acad. Sci. USA 86: 1244-1248.

Holton, T. A., and Cornish, E. C. 1995. Genetics and biochemistry of anthocyanin biosynthesis. Plant Cell 7:1071-1083.

Hu, C., Chen, K., Shi, Q., Kilkuskie, R., Cheng, Y., and Lee, K. 1994. Anti-AIDS agents. 10. Acatin-7-0-beta-D-galactopyranoside, an antiHIV principle from Chrysanthemum morifolium and a structureactivity correlation with some related flavonoids. J. Nat. Prod. 57:4251.

Jacobs, M., and Rubery, P. H. 1988. Naturally-occurring auxin transport regulators. Science 241:346-349.

Journet, E. P., Pichon, M., Dedieu, A., De Billy, F., Truchet, G., and Barker, D. G. 1994. Rhizobium meliloti Nod factors elicit cell-specific transcription of the Enod12 gene in transgenic alfalfa. Plant J. 6:241249.

Li, Y. G., Tanner, G., and Larkin, P. 1996. The DMACA-HCL protocol and the threshold proanthocyanidin content for bload safety in forage legumes. J. Sci. Food Agric. 70:89-101.

Long, S. R. 1996. Rhizobium symbiosis: Nod factors in perspective. Plant Cell 8:1885-1898.

Mabry, T. J., Markham, K. R., and Thomas, M. B., eds. 1970. The Systematic Identification of Flavonoids. Springer Verlag, Berlin.

Maxwell, C. A., Harrison, M. J., and Dixon, R. A. 1993. Molecular characterization and expression of alfalfa isoliquiritigenin 2'-Omethyltransferase, an enzyme specifically involved in the biosynthesis of an inducer of Rhizobium meliloti nodulation genes. Plant J. 4:971-981.

McClure, J. 1975. Physiology and functions of flavonoids. Pages 9901055 in: The Flavonoids. J. B. Harborne and T. J. Mabry, eds. Academic Press, New York.
McKhann, H., and Hirsch, A. 1994. Isolation of chalcone synthase and chalcone isomerase cDNAs from alfalfa (Medicago sativa L.): Highest transcript levels occur in young roots and root tips. Plant Mol. Biol. 24:767-777.

Mylona, P., Pawlowski, K., and Bisseling, T. 1995. Symbiotic nitrogen fixation. Plant Cell 7:869-885.

Munos, J. A., Palomares, A. J., and Ratet, P. 1996. Plant genes induced in the Rhizobium-legume symbiosis. World J. Microbiol. 12:189-202.

Oommen, A., Dixon, R. A., and Paiva, N. 1994. The elicitor inducible alfalfa isoflavone reductase promoter confers different patterns of developmental expression in homologous and heterologous transgenic plants. Plant Cell 6:1789-1803.

Paiva, N., Edwards, R., Sun, Y., Hrazdina, G., and Dixon, R. 1991. Stress responses in alfalfa (Medicago sativa L.) 11. Molecular cloning and expression of alfalfa isoflavone reductase, a key enzyme of isoflavonoid phytoalexin biosynthesis. Plant Mol. Biol. 17:653-667.

Pathirana, M. S., Samac, D. A., Roeven, R., Yoshioka, H., Vance, C. P., and Gantt, J. S. 1997. Analyses of phosphoenolpyruvate carboxylase gene structure and expression in alfalfa nodules. Plant J. 12:293-304.

Pawlowski, K., and Bisseling, T. 1996. Rhizobial and actinorhizal symbioses: What are the shared features? Plant Cell 8:1899-1923.

Phillips, D. A., Dakora, F. D., Leon-Barios, M., Sande, E., and Joseph, C. M. 1993. Signals released from alfalfa regulate microbial activities in the rhizosphere. Pages 197-202 in: New Horizons in Nitrogen Fixation. R. Palacios, J. Mora, and W. E. Newton, eds. Kluwer Academic, Dordrecht, The Netherlands.

Purohit, S., Laloraya, M. M., Bharti, S., and Nozzolillo, C. 1992. Effect of phenolic compounds on ABA-induced changes in $\mathrm{K}+$ concentration of guard cells and epidermal diffusive resistance. J. Exp. Bot. 43: 103-110.

Quandt, H.-J., Pülher, A., and Broer, I. 1993. Transgenic root nodules of Vicia hirsuta: A fast and efficient system for the study of gene expression in indeterminate-type nodules. Mol. Plant-Microbe Interact. 6: 699-706.

Ramwell, P. W., Sherratt, H. S. A., and Leonard, B. E. 1964. The physiology and pharmacology of phenolic compounds in animals. Pages 457-510 in: Biochemistry of Phenolic Compounds. J. Harborne, ed. Academic Press, London.

Ravanel, P., Creuzet, S., and Tissut, M. 1990. Inhibitory effect of hydroxyflavones on the exogenous NADH dehydrogenase of plant mitochondrial inner membranes. Phytochemistry 29:441-445.

Recourt, K., Verkerke, M., Schripsema, J., van Brussel, A. A. N., Lugtenberg, B. J. J., and Kijne, J. W. 1992. Major flavonoids in uninoculated and inoculated roots of Vicia sativa subsp. nigra are four conjugates of the nodulation gene-inhibitor kaempferol. Plant Mol. Biol. 18:505-513.

Sallaud, C., El-Turk, J., Breda, C., Buffard, D., de Kozak, I., Esnault, R., and Kondorosi, A. 1995. Differential expression of cDNA coding for chalcone reductase, a key enzyme of the 5-deoxyflavonoid pathway, under various stress conditions in Medicago sativa. Plant Sci. 109:179-190.

Schultze, M., Kondorosi, E., Ratet, P., Buiré, M., and Kondorosi, A. 1994. Cell and molecular biology of Rhizobium-plant interaction. Int. Rev. Cytol. 156:1-75.

Shirley, B. W. 1996. Flavonoid biosynthesis: "New" functions for an "old" pathway. Trends Plant Sci. 1:377-381.

Stenlid, G. 1963. The effects of flavonoid compounds on oxidative phosphorylation and on the enzymatic destruction of indole acetic acid. Physiol. Plant. 16:110-120.

Stenlid, G. 1968. On the physiological effects of phloridzin, phloretin and some related substances upon higher plants. Physiol. Plant. 21: 882-894.

Strack, D., Heilemann, J., Mömken, M., and Wray, V. 1988. Cell wallconjugated phenolics from coniferae leaves. Phytochemistry 27:35173521.

Tiller, S. A., Parry, A. D., and Edwards, R. 1994. Changes in the accumulation of flavonoid and isoflavonoid conjugates associated with plant age and nodulation in alfalfa (Medicago sativa). Physiol. Plant. 91:27-36.

Trinh, T. H., Ratet, P., Kondorosi, E., Durand, P., Kamate, K., Bauer, P., and Kondorosi, A. 1998. Rapid and efficient transformation of diploid Medicago truncatula and Medicago sativa ssp. falcata lines improved in somatic embryogenesis. Plant Cell Rep. 17:345-355.

Vasse, J., de Billy, F., Camut, S., and Truchet, G. 1990. Correlation be- 
tween ultrastructural differentiation of bacteroids and nitrogen fixation in alfalfa nodules. J. Bacteriol. 172:4295-4306.

Vasse, J., de Billy, F., and Truchet, G. 1993. Control of infection in the alfalfa-Rhizobium meliloti symbiosis. Pages 381-384 in: Advances in Molecular Genetics of Plant-Microbe Interactions. E. W. Nester and D. P. S. Verma, eds. Kluwer Academic, Dordrecht, The Netherlands.

Vijn, I., Christiansen, H., Lauridsen, P., Kardailsky, I., Quandt, H.-J., Broer, I., Drenth, J., Jensen, E. O., van Kammen, A., and Bisseling, T. 1995. A 200 bp region of the pea ENOD12 promoter is sufficient for nodule-specific and Nod factor induced expression. Plant Mol. Biol. 28:1103-1110.

Wang, C., Makela, T., Hase, T., Adlercreutz, H., and Kurzer, M. 1994. Lignans and flavonoids inhibit aromatase enzyme in human preadipocytes. J. Steroid Biochem. Mol. Biol. 50:205-212.
Weber, B., Hoesch, L., and Rast, D. M. 1995. Protocatechualdehyde and other phenols as cell wall components of grapevine leaves. Phytochemistry 40:433-437.

Yang, W., Canter Cremers, H. C. J., Hogendijk, P., Katinakis, P., Wijffelman, C. A., Franssen, H., Van Kammen, A., and Bisseling, T. 1992. In situ localization of chalcone synthase mRNA in pea root nodule development. Plant J. 2:143-151.

Zhang, K., and Das, N. 1994. Inhibitory effects of plant polyphenols on rat liver glutathione S-transferases. Biochem. Pharmacol. 47:20632068.

Zuanazzi, J. A. S., Clergeot, P. H., Quirion, J.-C., Husson, H.-P., Kondorosi, A., and Ratet, P. 1998. Production of Sinorhizobium meliloti nod gene activator and repressor flavonoids from Medicago sativa roots. Mol. Plant-Microbe Interact. 11:784-794. 